\title{
Sliding Wear Performance Evaluation of Red Mud (RM), RM + Fly Ash (FA) and RM + FA + Al Coatings on Mild Steel
}

\author{
Harekrushna Sutar 1,2,3*, Debashis Roy², Subash Chandra Mishra ${ }^{3}$, Rabi Ranjan Murmu ${ }^{1}$ \\ ${ }^{1}$ Chemical Engineering Department, Indira Gandhi Institute of Technology, Sarang, India \\ ${ }^{2}$ Chemical Engineering Department, Jadavpur University, Kolkata, India \\ ${ }^{3}$ Metallurgical and Materials Engineering Department, National Institute of Technology, Rourkela, India \\ Email: "h.k.sutar@gmail.com
}

Received 16 February 2016; accepted 18 March 2016; published 21 March 2016

Copyright (C) 2016 by authors and Scientific Research Publishing Inc.

This work is licensed under the Creative Commons Attribution International License (CC BY). http://creativecommons.org/licenses/by/4.0/

(c) (i) Open Access

\section{Abstract}

The research paper focuses on evaluating the dry sliding wear behaviour of plasma sprayed coatings like red mud (RM), RM + 5\% Fly Ash (FA) and RM + 5\% FA + 5\% Al on mild steel cylindrical shape substrate. Spraying was done at $10 \mathrm{~kW}$ operating power level. A conventional pin on disc wear tester is adopted for wear analysis. The wear test was performed at track diameter of $50 \mathrm{~mm}$ and sliding speed of $60 \mathrm{rpm}(0.157 \mathrm{~m} / \mathrm{s})$ with normal load of $10 \mathrm{~N}$. The duration of sliding varies from 54 minutes for pure red mud coating to a maximum value of 102 minutes for $\mathrm{RM}+\mathbf{5 \%} \mathrm{FA}+$ $5 \%$ Al composite coating. A significant decrease in wear rate (in terms of mass loss) is observed by reinforcement of fly ash and aluminium to red mud, which might be due to improved interfacial properties.

\section{Keywords}

Red Mud, Fly Ash, Aluminium, Plasma Coating, Sliding Wear, Frictional Force

\section{Introduction}

Coating technology is an emerging research in engineering application. Wear resistive materials are fabricated by means of coating for wide tribological applications. Plasma spraying technology is widely adopted for coating thereby enhancing the surface properties. Surfaces with coating can protect from abrasive, adhesive and corrosive wear mediums. Commonly conventional coating materials are nickel, iron, cobalt and molybdenum

\footnotetext{
${ }^{*}$ Corresponding author.
} 
based alloys, and carbides of ceramic and tungsten [1] [2].

Several factors may influence the tribological behaviour of a coated surface. Such as geometry of contact, material characteristics, basic mechanical properties, operating parameters controlling the coating deposition and finally the microstructure [3]. Ceramic coatings are also proved to be favourable towards better tribological application. Tribological performance at high temperature of ceramic coatings is available [4], showing high wear resistance [5]. But ceramic coatings exhibit failure mechanisms like plastic deformation, brittle fracture and polish effect [6], which in turn demands reinforcement of additives which could reduce the friction and wear of plasma sprayed ceramic coatings. The importance of mechanical and tribological properties has convinced many researchers to study the friction and wear behaviour and to improve the wear resistance of composite coatings [7]. Composite coatings can be considered to be one of the competitive materials for tribological applications because of their low friction values against steel counterparts, good damping properties, and self-lubricating abilities [8].

The resources of red mud and its comprehensive utilizations are reviewed [9]. Red mud as an industrial waste material may be considered to be the material of choice for coating applications for replacing some conventional expensive coating materials. Few results on the basis of sliding wear behaviour of red mud were being reported [10]. Morphology and solid particle erosion wear behaviour of red mud and fly ash composite coatings were being available in the literature [11]. Dry sliding wear behaviour of rice husk and red mud filled epoxy composites is described [12]. Friction and dry sliding wear behaviour of red mud filled banana fibre reinforced unsaturated polyester composites is reported [13]. Tribological studies on red mud reinforced aluminium metal matrix composites are disclosed [14]. The characteristics of plasma sprayed pure red mud coating surface are reported [15]. Wear behaviours of plasma sprayed red mud coatings made at $9 \mathrm{~kW}$ operating power level, reinforced with varying weight \% of fly ash, aluminium, carbon have been analysed at different operating conditions [16]. The objective of this research work is to study the mechanical and dry sliding wear behaviour of red mud coatings reinforced with additives like fly ash and fly ash + aluminium separately and comparing the results, inciting red mud (with additives like fly ash and aluminium) as suitable coating material may be implemented for replacing the conventional coatings.

\section{Materials and Methods}

\subsection{Raw Materials, Sample Preparation and Coating}

The primary raw material for the study is red mud (RM). The red mud powder was collected from National Aluminium Company (NALCO), Damonjodi, Odisha, India. The additive like fly ash was obtained from Rourkela steel plant. Aluminium powder was procured from Rourkela market. After obtaining the precursor, the same was dried to make it moisture free. Powders chosen for plasma spraying are tabulated in Table 1.

Each raw material was sieved to obtain a particle size range of $80-100 \mu \mathrm{m}$ and thoroughly blended to obtain uniformity in composition. The substrate selected for plasma coating is of mild steel. Commercially available mild steel rod was chopped to pieces of cylindrical dimension having $l=30 \mathrm{~mm}$ and $\Phi=10 \mathrm{~mm}$. Spraying was done on both the cross section of the specimen. The average roughness of the specimen cross section is $7.2 \mu \mathrm{m}$. Specimens were pre cleaned in ultrasonic cleaning unit before plasma spraying. The raw materials were thermally sprayed using atmospheric plasma spraying technique. The parameters governing the spraying process are reported in Table 2.

\subsection{Friction and Wear Test Apparatus}

Dry sliding wear tests were carried out using a pin on disc friction and wear monitor test ring (DUCOM) according to ASTM G 99 standard. The cylindrical substrates with coating on both the cross sections were tested against a disc made of hardened ground steel (EN-32, hardness 72 HRC, surface roughness Ra $=0.07 \mu \mathrm{m}$ ). The schematic diagram of the pin on disc wear tester is shown in Figure 1.

The cylindrical test specimen was held stationary and hardened disc rotates anticlockwise against it. A normal force was applied on the test specimen by means of pulley, lever and spring mechanism. All wear experiments were carried out at normal atmospheric temperature and pressure. A normal load of $10 \mathrm{~N}$ was applied on substrate keeping track diameter at $50 \mathrm{~mm}$ and sliding speed of $60 \mathrm{rpm}$ (At a velocity of $0.157 \mathrm{~m} / \mathrm{s}$ ). Wear rates are expressed in terms of mass loss in mg. Frictional force (F) was calculated directly from the apparatus in Kg. 
Table 1. Powders used for coating.

\begin{tabular}{ccc}
\hline Sl. No & Coating powder & Composition by weight \% \\
\hline 1 & Red mud (RM) & 100 \\
2 & RM + Fly ash (FA) & $95+5$ \\
3 & RM + FA + Al & $90+5+5$ \\
\hline
\end{tabular}

Table 2. Variables during plasma sprayed coating.

\begin{tabular}{cc} 
Operating variables & Set point \\
\hline Plasma arc current ( ampere) & 200 \\
Arc voltage (Volt) & 50 \\
Torch input power (kW) & 10 \\
Plasma gas (Argon) flow rate (Litre/Min) & 20 \\
Powder feed rate (gm/min) & 10 \\
Torch to base distance (mm) & 120 \\
Arc length range (mm) & $3,6,9,13$ \\
Spray angle (In degree) & 90
\end{tabular}

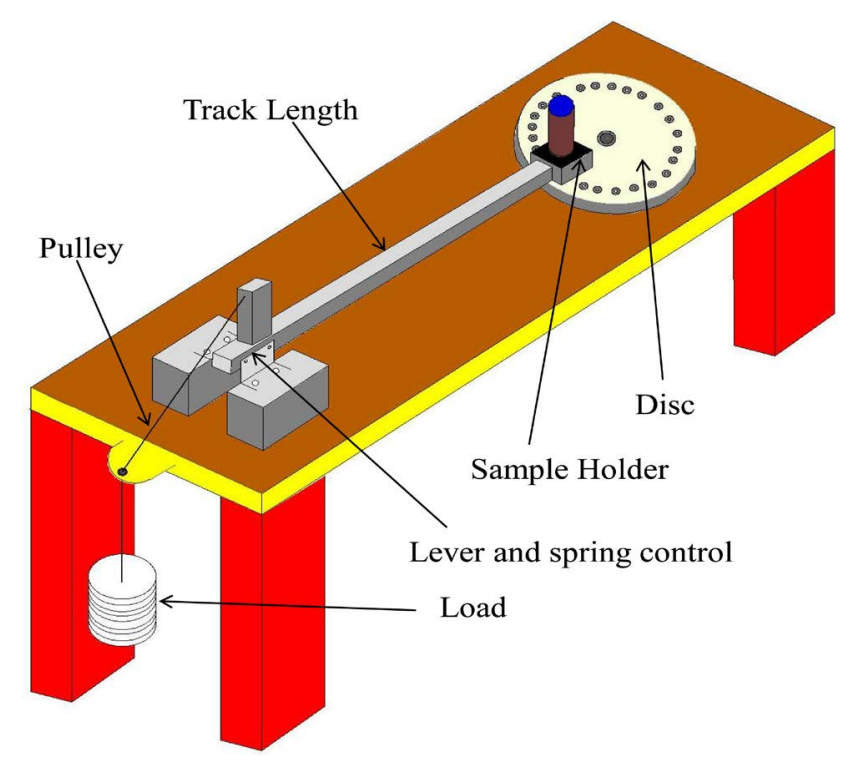

Figure 1. Model of pin on disc wear test rig.

\section{Results and Discussion}

\subsection{SEM, XRD and EDS Report}

The Characterization of red mud powder was done using a SEM (Scanning electron microscope, JEOL; JSM6480 LV). The captured image and EDS (Energy dispersive spectroscopy) reports are shown in Figure 2.

The elemental analysis report is composed in Table 3 indicating weight (normalised) and atomic \% (unnormalised) of elements comprising red mud powder. The major constituents prevailing in red mud are $\mathrm{Fe}$ and Ti. Minor constituents like $\mathrm{Na}, \mathrm{O}, \mathrm{Mg}, \mathrm{Si}, \mathrm{K}$ and $\mathrm{Cr}$ are also visible.

Further Characterization of red mud powder was carried by means of X-RD. The X-Ray diffractogram was captured using a Philips X-Ray diffractometer. The report is shown in Figure 3. The major phases found in red mud powder were Hematite $\left(\mathrm{Fe}_{2} \mathrm{O}_{3}\right)$, Silicon dioxide $\left(\mathrm{SiO}_{2}\right)$, Titanium dioxide $\left(\mathrm{TiO}_{2}\right)$. The coatings are additionally recognized by means of EDS report. To perceive the significance; the EDS (Figure 4) and interlayer cross sectional sight (Figure 5) are reported for RM + 5\% FA coating. 


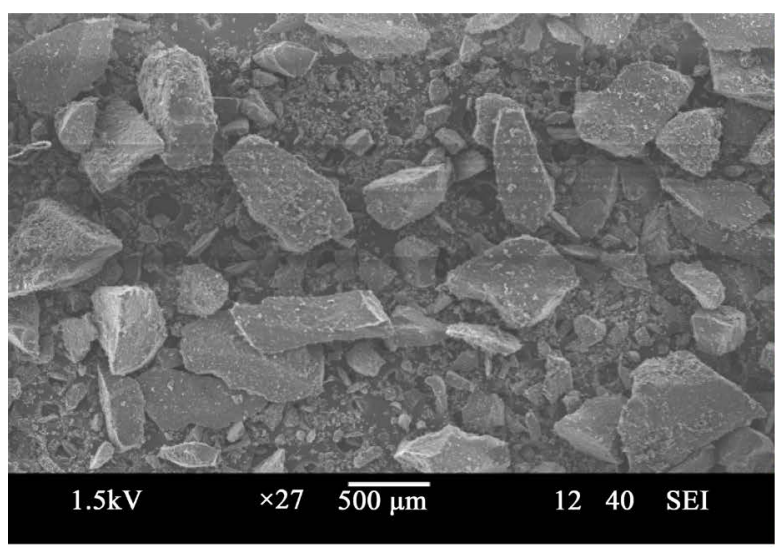

(a)

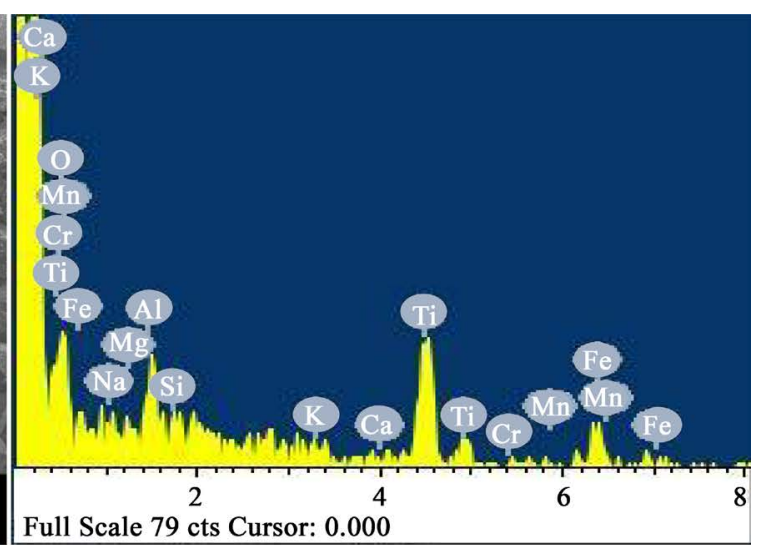

(b)

Figure 2. (a) SEM; (b) EDS of red mud powder.

Table 3. Elemental analysis report of red mud powder.

\begin{tabular}{ccc}
\hline Element & Weight \% & Atomic \% \\
\hline O K & 0.70 & 1.90 \\
Na K & 1.77 & 3.35 \\
Mg K & 2.41 & 4.32 \\
$\mathrm{Al} \mathrm{K}$ & 7.76 & 12.54 \\
Si K & 3.88 & 6.02 \\
K K & 0.71 & 0.79 \\
Ca K & 1.19 & 1.29 \\
Ti K & 46.63 & 42.44 \\
Cr K & 0.68 & 0.57 \\
Mn K & 1.76 & 1.40 \\
Fe K & 32.53 & 25.39 \\
Totals & 100 & \\
\hline
\end{tabular}

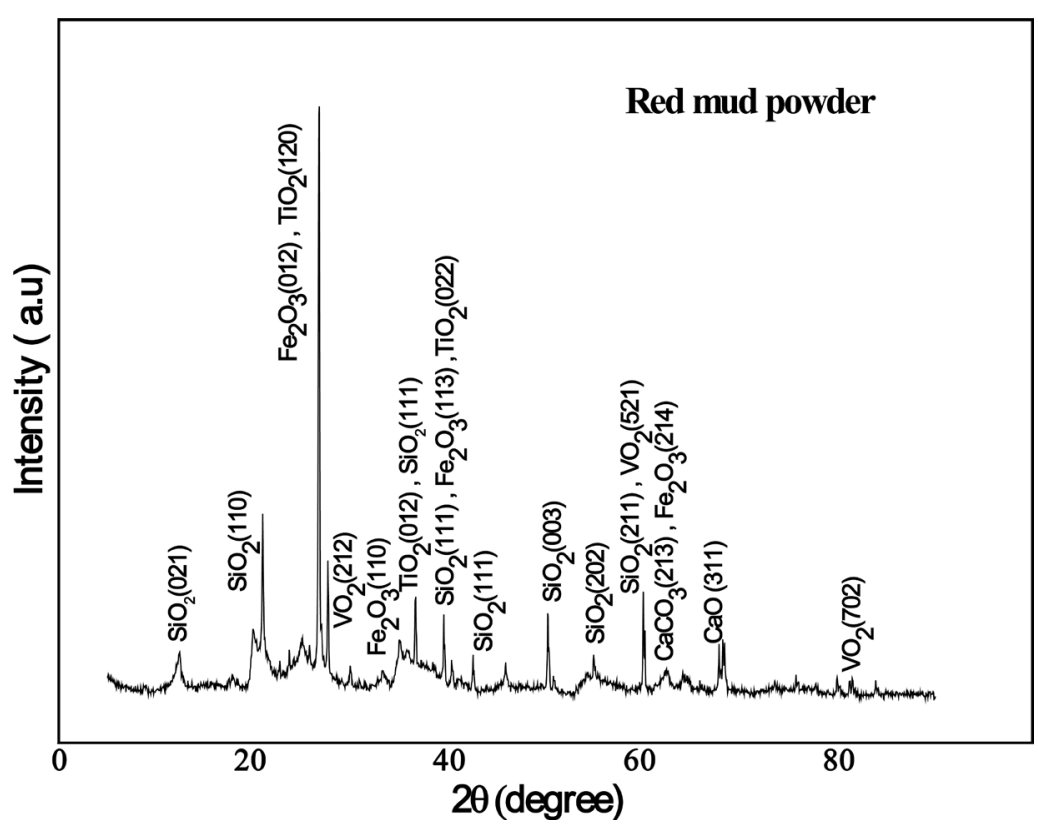

Figure 3. XRD of red mud powder. 


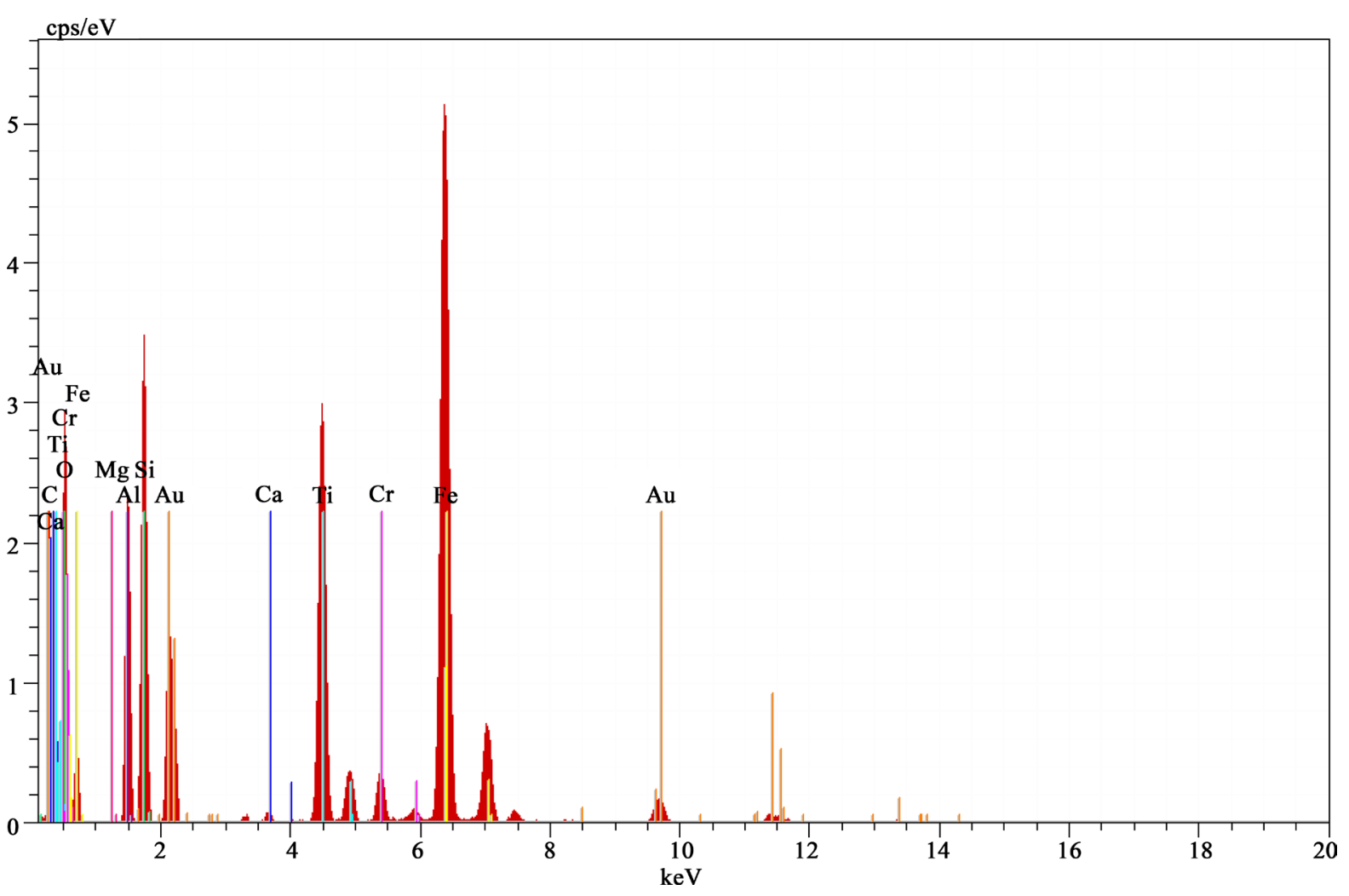

Figure 4. EDS outline for RM + 5\% FA coating.

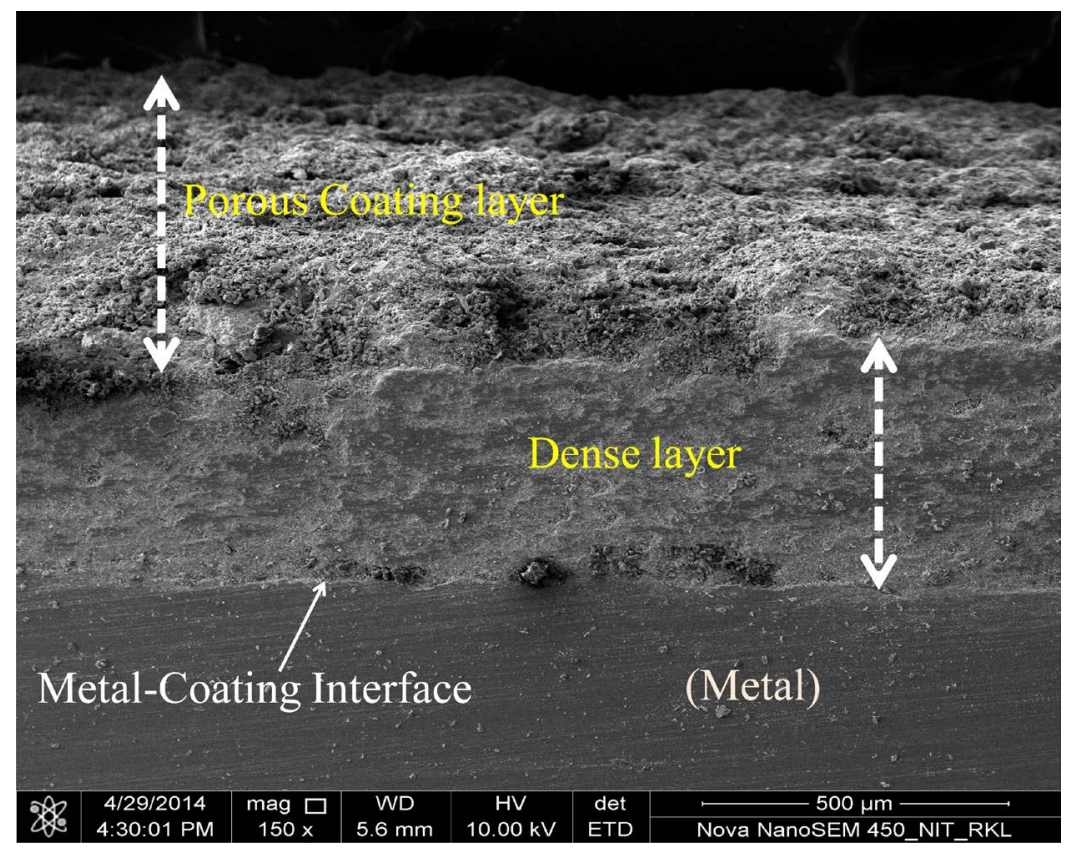

Figure 5. Snap shot of cross section for RM + 5\% FA coating.

The morphology of each coating type was studied using FESEM (Field emission scanning electron microscope, NOVA Nano SEM-450). The captured images are shown in Figure 6. All the coatings were made at 10 kW operating power level. Figure 6(a) represents the morphology template for pure red mud coating. Very large size globular particles with non uniformity of interface were seen. Few semi molten small particles were 


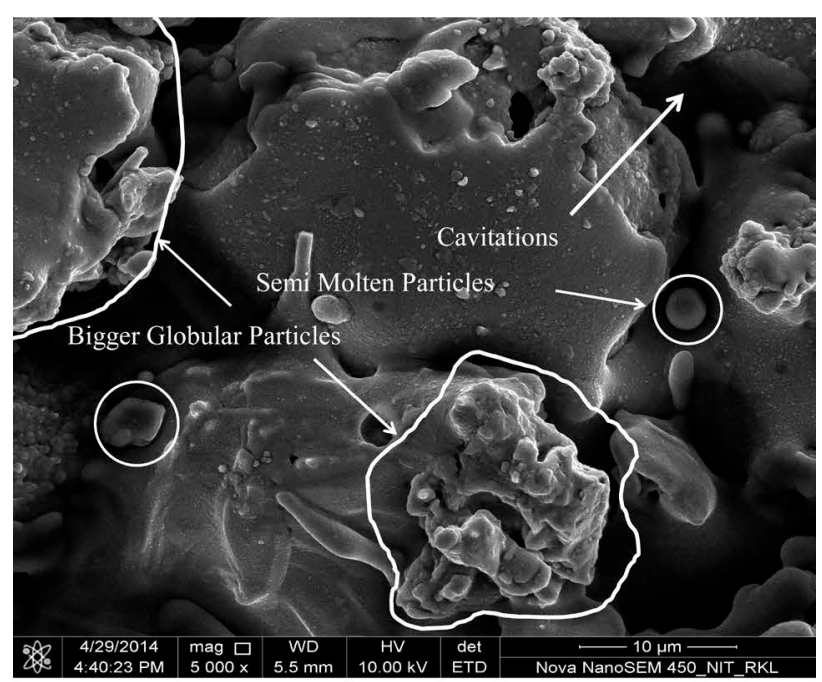

(a)

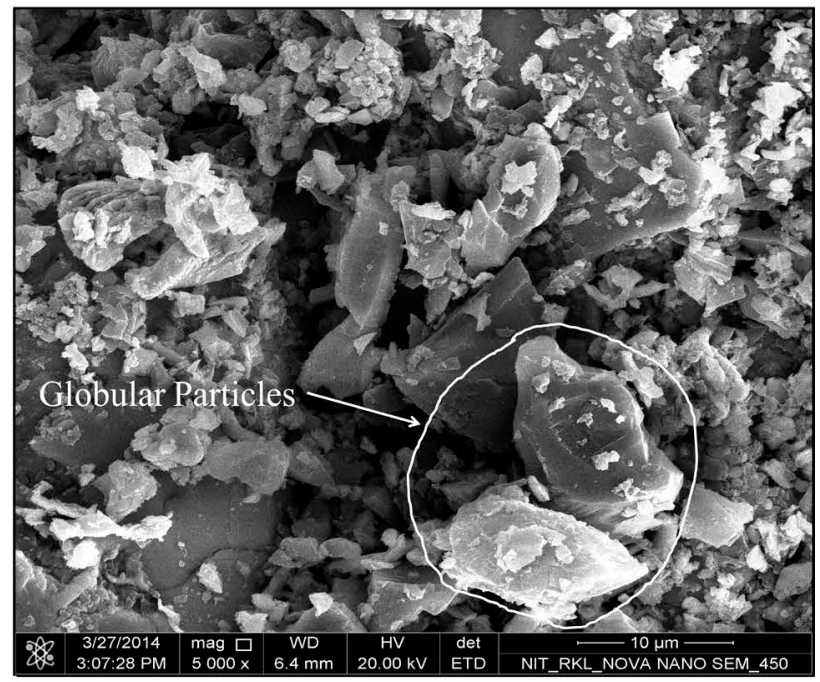

(b)

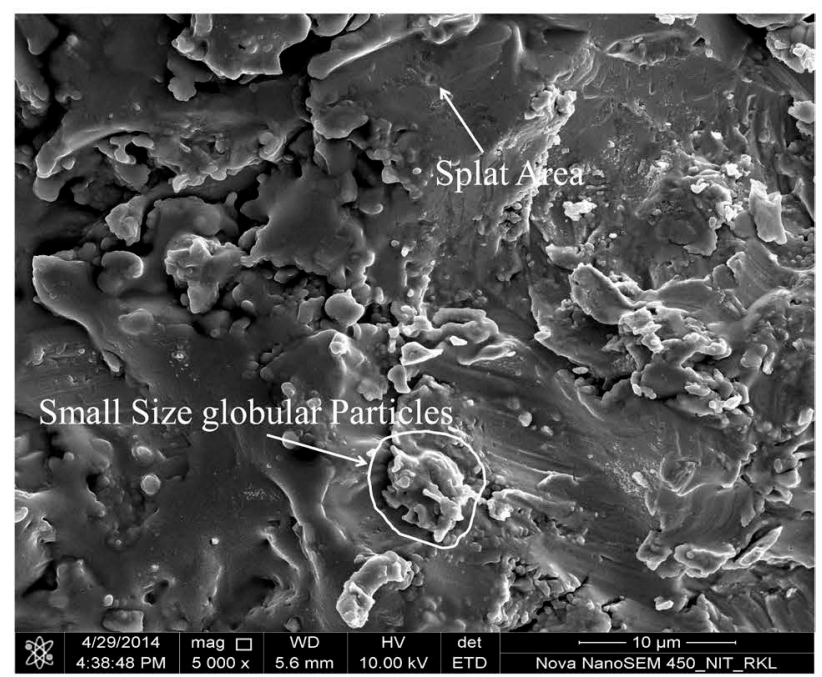

(c)

Figure 6. Morphology of coatings (a) RM, (b) RM + 5\% FA and (c) RM + 5\% FA + 5\% Al. 
also visible. Large scale cavity areas were found. As the composition changes to RM $+5 \%$ FA, very marginal changes in morphology pattern (Figure 6(b)) were observed. Similar cavities were found. But the numbers of semi molten particles were reduced. Smaller size globular particles were also visible. Finally as $5 \% \mathrm{Al}$ was reinforced to RM + 5\% FA composite, the coating surface format (Figure 6(c)) significantly affected. Uniformity of the surface was improved. Formation of cavity was fallen. But still very small size globular particles were seen.

\subsection{Wear Rate and Frictional Force Analysis}

At first the coating surfaces were cleaned with acetone using tissue paper for removing the embedded particles if any. Then substrates were analysed for wear loss fixing in the pin holder. The operating parameters were secured at its values as mentioned earlier. Figure 7 shows the trends of wear rate for all coating during the course of examination. At the beginning the red mud coatings were examined. The wear analysis was performed till the coating layer prevails on the metal interface. The total duration of wear for red mud was continued up to 54 minutes as late as the existence of coating film. In each 3 minutes time gap the wear loss (In terms of mass loss in $\mathrm{mg}$ ) was measured. A dramatic increase in mass loss was observed at incipient up to 36 minutes. There after the wear rate stabilises and the coating sheet terminates at 54 minutes.

An inclusion of 5\% FA to RM reduces the wear rate as visible in Figure 7. A similar trend of higher mass loss at beginning was seen. The mass loss declines at the final stage and a steady state was attained at 54 minutes. The survival of coating surface ends at 72 minutes. Coatings of $\mathrm{RM}+5 \% \mathrm{FA}+5 \% \mathrm{Al}$ were audited eventually; designating a minimum mass loss. As before, substantially a higher tendency to wear was informed. A steady mass loss was occurred at 84 minutes and the wear rate plot assumed a plateau. The coating surface holds out at 102 minutes. The results of wear rate may be due to the distinction of coating inter layer properties, signifying the inequality of interfacial bond strength for each coating type. In other words for RM $+5 \% \mathrm{FA}+5 \% \mathrm{Al}$ coating, there might be proper particle to particle bonding; which in turn augmented the interfacial tension, molecular bond strength as well as density and recasting to high wear resistive. The data pertaining to the force of friction (F) is reported in Figure 8.

Wear morphology for stipulated coating samples were captured. Figure 9 shows the wear morphology for $\mathrm{RM}+5 \%$ FA coating after 15 and 30 minutes of sliding. Worn surfaces for RM $+5 \% \mathrm{FA}+5 \% \mathrm{Al}$ coating at the end of 18 and 90 minutes sliding are pictured in Figure 10. Wear debris particles were visible on the worn surfaces with few cracked sections, winding up; the wear takes up by abrasive and adhesive mechanism.

\section{Conclusion}

The above available research remarks a noteworthy accomplishment. The red mud, an industrial waste from

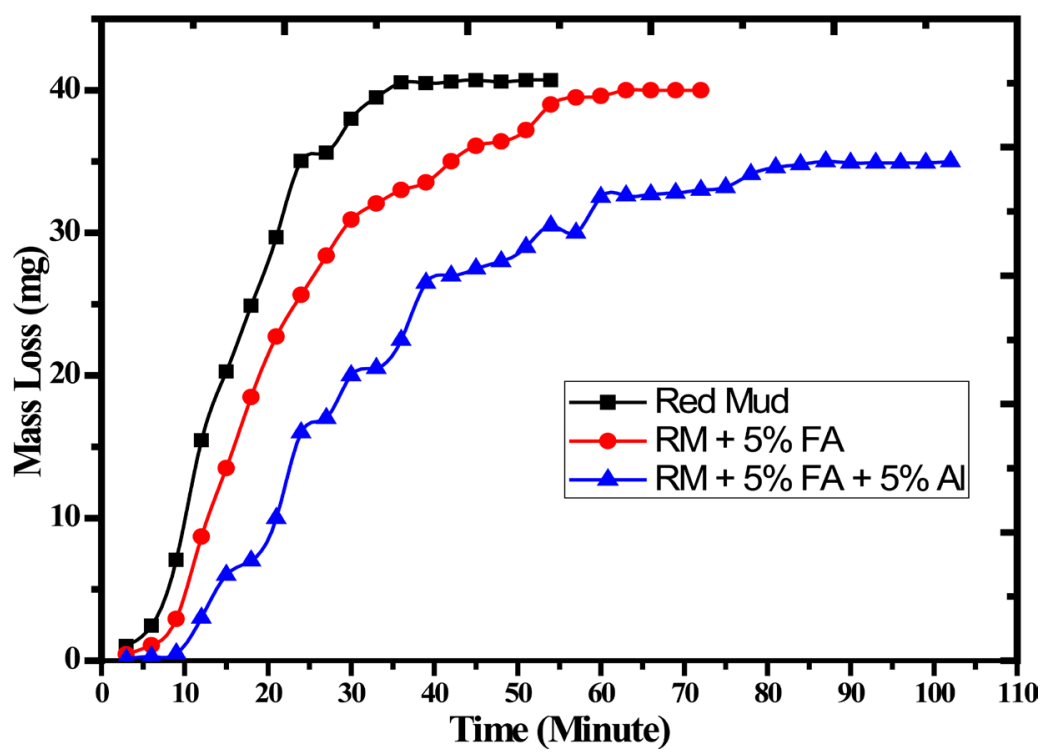

Figure 7. Wear rate plot for coatings. 


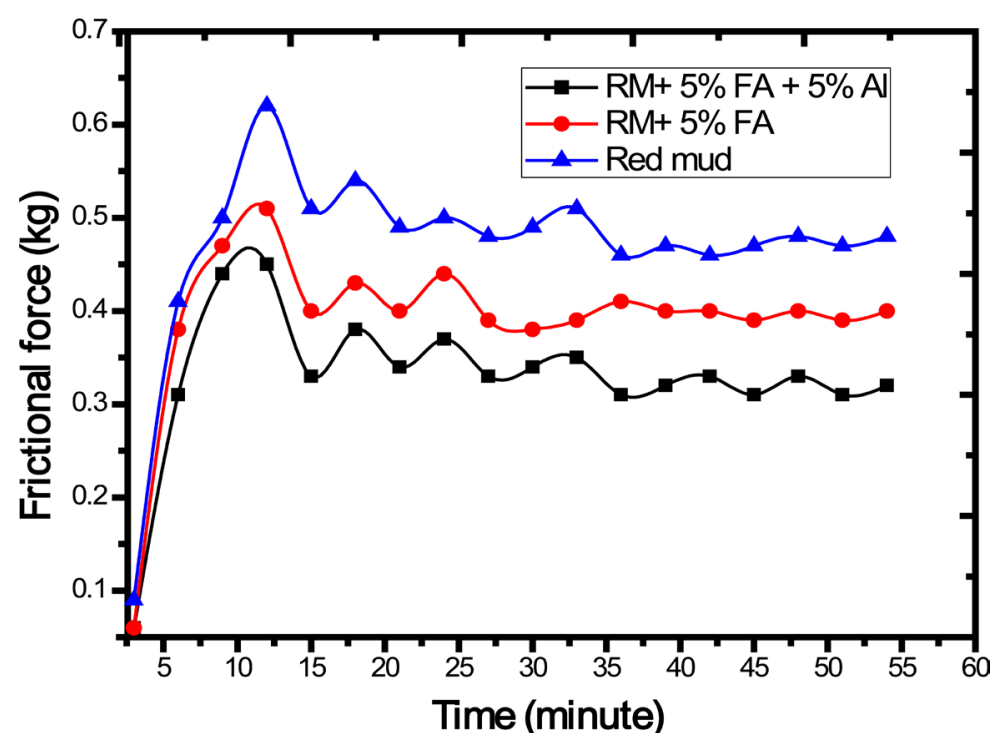

Figure 8. Variation of force of friction.

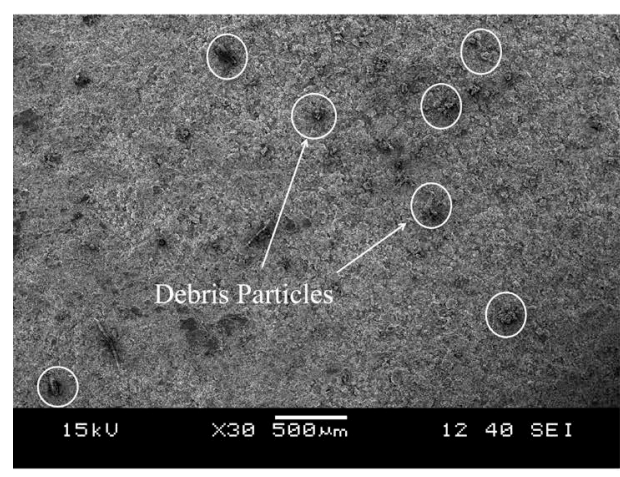

(a)

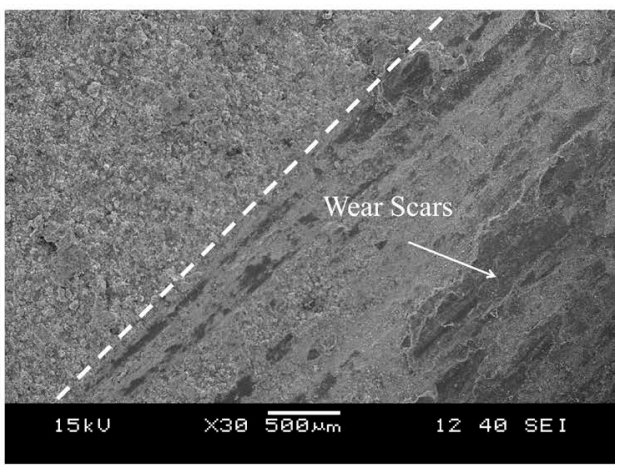

(b)

Figure 9. Wear morphology for RM + 5\% FA coating after (a) 15 and (b) 30 minutes of sliding.

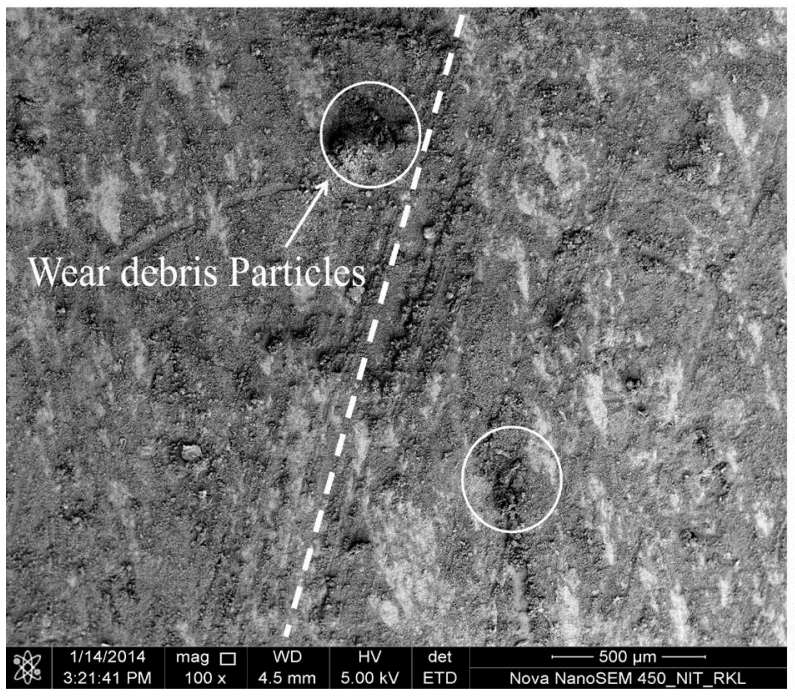

(a)

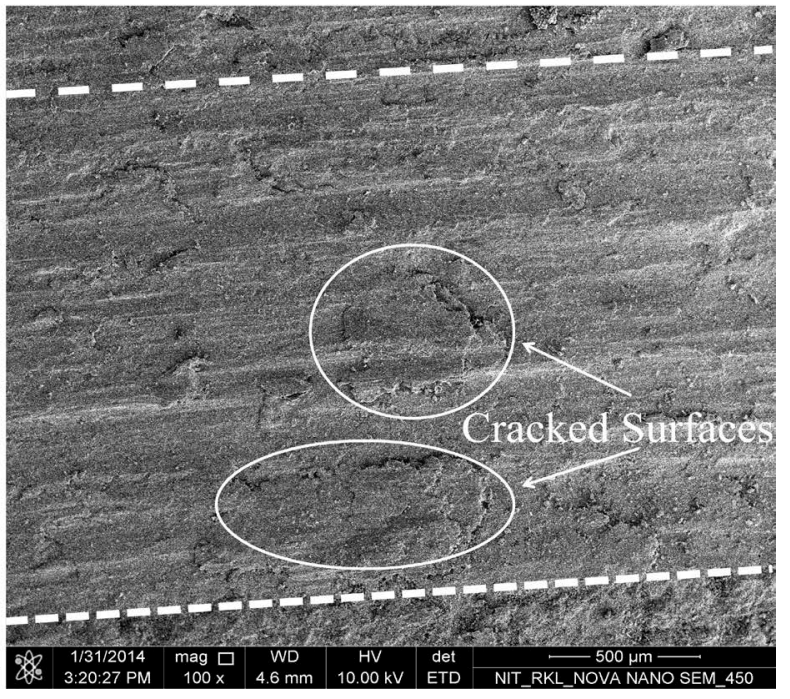

(b)

Figure 10. Worn surfaces for RM + 5\% FA+ 5\% Al coating after (a) 18 and (b) 90 minutes of sliding. 
alumina plant is proved to be conveniently coat able on metal like mild steel; and might be an alternative source for replacing conventional coating materials. Additives like fly ash and aluminium boost up the surface properties by modifying the physical and interfacial characteristics. The extended road map for the researchers could be to find out suitable tribological application areas. Studies on evaluating the resistance towards corrosive wear in different environmental conditions could be implemented. A subsequent inspection on the effect of heat treatment and high temperature application of these coatings may be emphasized.

\section{References}

[1] Kushner, B.A. and Novinski, E.R. (1992) Thermal Spray Coating. Friction, Lubrication and Wear Technology, 18, 829-833.

[2] Crook, P. (1992) Friction and Wear of Hard Facing Alloys. Vol.18 of ASM Handbook, ASTM International.

[3] Holmberg, K, Matthews, A. and Ronkainen, H. (1998) Coatings Tribology-Contact Mechanisms and Surface Design. Tribology International, 31, 107-120. http://dx.doi.org/10.1016/S0301-679X(98)00013-9

[4] Wang, Y., Jin, Y. and Wen, S. (1988) The Analysis of the Friction and Wear Mechanisms of Plasma-Sprayed Ceramic Coatings at $450^{\circ} \mathrm{C}$. Wear, 128, 265-276. http://dx.doi.org/10.1016/0043-1648(88)90063-4

[5] Wang, Y., Jin, Y. and Wen, S. (1998) The Analysis of the Chemicalstructure and Properties of Ceramic Surface Films in Friction Using SEM, AES and Micro-Region X-Ray Diffraction. Wear, 128, 277-290. http://dx.doi.org/10.1016/0043-1648(88)90064-6

[6] Vijande-Diaz, R., Belzunce, J., Fernandez, E., Rincon, A. and Perez, M.C. (1991) Wear and Microstructure in Fine Ceramic Coatings. Wear, 148, 221-233. http://dx.doi.org/10.1016/0043-1648(91)90286-4

[7] Kumar, S. and Chauhan, S.R. (2012) Mechanical and Dry Sliding Wear Behavior of Particulate Fillers $\mathrm{CaCO}_{3}$ and $\mathrm{CaSO}_{4}$ Filled Vinyl Ester Composites. International Journal of Composite Materials, 2, 101-114. http://dx.doi.org/10.5923/j.cmaterials.20120205.06

[8] Lackner, J.M., Waldhauser, W., Major, L. and Kot, M. (2004) Tribology and Micromechanics of Chromium Nitride Based Multilayer Coatings on Soft and Hard Substrates. Coatings, 4, 121-138.

http://dx.doi.org/10.3390/coatings4010121

[9] Sutar, H., Mishra, S.C., Sahoo, S.K., Chakraverty, A.P. and Maharana, H.S. (2014) Progress of Red Mud Utilization: An Overview. American Chemical Science Journal, 4, 255-279. http://dx.doi.org/10.9734/ACSJ/2014/7258

[10] Sutar, H., Roy, D., Mishra, S.C., Chakraverty, A.P. and Maharana, H.S. (2015) Friction and Wear Behaviour of Plasma Sprayed Fly Ash Added Red Mud Coatings. Physical Science International Journal, 5, 61-73. http://dx.doi.org/10.9734/PSIJ/2015/12624

[11] Sutar, H., Mishra, S.C., Sahoo, S.K., Satapathy, A. and Kumar, V. (2012) Morphology and Solid Particle Erosion Wear Behavior of Red Mud Composite Coatings. Natural Science, 4, 832-838. http://dx.doi.org/10.4236/ns.2012.411111

[12] Rout, A. and Satapathy, A. (2012) Analysis of Dry Sliding Wear Behaviour of Rice Husk Filled Epoxy Composites Using Design of Experiment and ANN. Procedia Engineering, 38, 1218-1232. http://dx.doi.org/10.1016/j.proeng.2012.06.153

[13] Prabu, V.A., Manikandan, V. and Uthayakumar, M. (2012) Friction and Dry Sliding Wear Behavior of Red Mud Filled Banana Fibre Reinforced Unsaturated Polyester Composites Using Taguchi Approach. Materials Physics and Mechanics, 15, 34-45.

[14] Prasad, N., Sutar, H., Mishra, S.C., Sahoo, S.K. and Acharya, S.K. (2013) Dry Sliding Wear Behavior of Aluminium Matrix Composite Using Red Mud an Industrial Waste. International Research Journal of Pure and Applied Chemistry, 3, 59-74. http://dx.doi.org/10.9734/IRJPAC/2013/2906

[15] Satapathy, A., Sutar, H., Mishra, S.C. and Sahoo, S.K. (2013) Characterization of Plasma Sprayed Pure Red Mud Coatings: An Analysis. American Chemical Science Journal, 3, 151-163. http://dx.doi.org/10.9734/ACSJ/2013/3218

[16] Sutar, H., Roy, D. and Mishra, S.C. (2015) Effect of Fly Ash and Carbon Reinforcement on Dry Sliding Wear Behaviour of Red Mud. Indian Journal of Materials Science, 2015, Article ID: 296324, 7 p. 